\title{
Online Social Networks - Opportunities for Empowering Cancer Patients
}

\author{
Zeinab Mohammadzadeh, Somayeh Davoodi, Marjan Ghazisaeidi*
}

\begin{abstract}
Online social network technologies have become important to health and apply in most health care areas. Particularly in cancer care, because it is a disease which involves many social aspects, online social networks can be very useful. Use of online social networks provides a suitable platform for cancer patients and families to present and share information about their medical conditions, address their educational needs, support decision making, and help to coping with their disease and improve their own outcomes. Like any other new technologies, online social networks, along with many benefits, have some negative effects such as violation of privacy and publication of incorrect information. However, if these effects are managed properly, they can empower patients to manage cancer through changing behavioral patterns and enhancing the quality of cancer patients lives This paper explains some application of online social networks in the cancer patient care process. It also covers advantages and disadvantages of related technologies.
\end{abstract}

Keywords: Cancer patients - online social networks - empowerment

Asian Pac J Cancer Prev, 17 (3), 933-936

\section{Introduction}

Because cancer diseases impose large costs to communities, so that preventing and minimizing the impact of these diseases is great challenge that modern society facing with (Mohammadzadeh et al., 2013a). Cancer is not only a personal disease and beside its great influences on many aspects of patient life (Abbasnezhad et al., 2015); it has socioeconomically impacts (Cannon et al., 2012). Raise individual awareness about cancer leads to prevention and early detection of cancer and reduce mentioned costs (Mohammadzadeh et al., 2015). Patients with cancer desire to obtain updated information about different aspects of their disease such as sign and symptoms, diagnosis, treatment, side effects of various methods of treatment, follow up and cancer effect on their life (Shahrokni et al., 2013). Modern IT based and internet solutions empower patients and provider to gain this purpose (Karver and Berger, 2010; Davoodi et al., 2015). Online social networks are an example of these solutions that have been grown dramatically in recent decades. For example in the U.S., rate of adults using these technologies has increased from $8 \%$ to $72 \%$ since 2005 (Ventola, 2014). The social networks witch link patients and health care providers have created a revolution in health care system by providing new methods of care delivery (Rowley, 2014).

In cancer care like other areas of health care, social networks have great influences in physician, nurse and patient activities. It rapidly have been adapted by people and made great changes in communication processes (Cain, 2011). In this paper online social networks and their effect on various aspects of life in patients with cancer have been described.

\section{Online social networks}

In recent decades the use of online social networks increases significantly because these powerful technologies decrease face to face visits and are accessible, inexpensive, user friendly and easy to use (Sugawara et al., 2012).

\section{Online social networks definitions}

Social media are mobile or internet base applications that gather and share information to facilitate communication between people (Von Muhlen and Ohno-Machado, 2012). Online social networks are one types of social media (Courtney, 2013) and they are sets of people with webbased social relationships that can create own public or semi-public profile within web site to connect other users and interchange information (Garton et al., 1997; Ellison, 2007; Steinfield et al., 2008). Some examples of online social networks applications are Twitter, Facebook, Myspace, Flicker and Instagram (Mislove et al., 2007; Steinfield et al., 2008; De la Torre-Diez et al., 2012; Cavallo et al., 2014; Attai et al., 2015).

\section{Social network sites categories}

Social network sites are used for different purpose including social networks (connect people with common 
interests such as Facebook, MySpace, Google Plus, Twitter), professional and academic networks (connect people with work-related context such as LinkedIn), multimedia sharing networks (share videos and photos such as YouTube, Flickr), educational and knowledge/ information aggregation networks (Wikipedia), Content production (blogs [Tumblr, Blogger] and microblogs [Twitter]) and virtual reality and gaming environments (Second Life) (Ellison et al., 2007; Scott, 2012; Rowley, 2014; Ventola, 2014).

\section{Roles of online social networks in cancer patient care}

Online social networks have a great potential for applying in the field of health according to some reasons including large amount of audiences, messages with greater impact than traditional strategies and high level on patient activity and participation (Maher et al., 2014). They are used for appointment setting, reporting test results, prescription notifications, and answering questions (Centola, 2013). In addition, advent of new generation of phones such as smart phones, mobile sensing devices and software applications with capability to share online and automatically information help online social networks to apply for cancer prevention and early detection programs (Cavallo et al., 2014).

Online social networks are modern technologies that help understanding people interactions and their activities and provide a fast way to find people who have the same experiences with cancer. The networks are used to online and simultaneously share information and experiences of sign and symptoms, diagnosis, treatment, adverse effects, care outcomes, medical evidences and life styles among individuals (Bakshy et al., 2012; Griffiths et al., 2012).

Cancer patients need information about their illness that help to improve treatment outcomes and increase patient participation in care process (Chelf et al., 2001). Addressing informational needs and patients education are the main parts of cancer patients care process (Harris, 1998). In recent years, use of the Internet and online social networks for quick access to health information among patients with cancer has been increased significantly (Azadmanjir et al., 2015). As well as social isolation reduces access to cancer care and health services for cancer patients; also studies show that high social relationship via social networks has positive effects on health status and treatment outcomes (Suarez et al., 2000; Yoon and Tourassi, 2014; Perkins et al., 2015).

In result due to rising cancer rates in the world, particularly in developing countries because of individual lifestyles (Haghdoost et al., 2014), policymakers should looking for innovative solutions such as social networks to define health priorities and effective cancer control by changing people's behavioral patterns (Mohammadzadeh et al., 2013b).

Online social network advantages in cancer patient care

Online social networks have many benefits for people and organizations. The main advantage of the social network is their capacity to transfer of best practices and usable experiences; in the other hand it can lead to behavioral changes in cancer patient for managing and controlling cancer (Suarez et al., 2000; Maher et al., 2014). Some examples of behavioral changes are having a healthful diet, leaving dangerous behavior such as smoking, alcohol consumption, inactivity, following regular and scheduled visits (Pinquart and Duberstein, 2010; Kim et al., 2015). All mentioned items can lead to enhance quality of life in cancer patients (Sapp et al., 2003; Kroenke et al., 2013).

Other benefits of online social networks for patient include, provide information in a similar situation for patients and their families, emotional support, share experiences of treatment between patients and their families, encouraging other cancer patients (Fernsler and Manchester, 1996), increase patient knowledge, decrease patient anxiety (Attai et al., 2015), present skill training with lower cost compared to other methods (DuBenske et al., 2010) and facilitate the communication between patients and providers (Griffiths et al., 2012).

Social networks by providing information resources help to rapid screening of cancer patients and lead to early detection of disease (Suarez et al., 1994; Ogedegbe et al., 2005; Lee et al., 2013). Studies show that providing different supportive activities through social networks may be able to increase survival rate and decrease mortality, disabilities and recurrence in cancer patients (Vogt et al., 1992; Kroenke et al., 2006; Lutgendorf et al., 2012).

\section{Online social network advantages in cancer patient education}

One of the main application of online social network in the health area is quick dissemination of education among patients. Health education has been reported to cause behavioral changes and performance promotion in both clinicians and patients (Glanz et al., 2008). Providing education for patient from cancer care providers can support cancer patient through reducing patient stress (Dunkel-Schetter, 1984) and have positive effects on treatment process and outcomes (Rainey, 1985; Chelf et al., 2001; Oliver et al., 2001).

Some educational benefits of online social networks for patients include provide educational information for population groups by using video and text sharing. These educational efforts empower patients self management, increse patient participation in care process, provide emotional supports and enhance patient safety (Ell, 1984; Househ et al., 2014).

\section{Online social networks disadvantages}

Although using online social networks have many advantages in the field of health especially in cancer care, but there are some negative aspect that need to regard. For example low and unsufficient quality of shared data and information (Ventola, 2014), Patient privacy and information confidentiality breach (Hader and Brown, 2010), problems of patient and provider relationships and legal issues (Centola, 2013; Ventola, 2014).Therefore it should be noted that unsuitable management and control of social networks may have adverse influence in cancer patients (Kroenke et al., 2012). 


\section{Conclusions}

Increasing patient access to medical information by modern technological methods such as online social networks have important influence on the decisions and behavior of patient with cancer (Shahrokni et al., 2013). These networksalso provide the required information for people in remote areas, increase accessibility and reducing social disparities (Freeman, 2004). Online social networks can empower cancer patients and extend patient community and facilitate discovering useful information.

In result online social networks help cancer patients to coping with their disease andempower them to make safer and healthier decisions and finally improve outcomes of care process.Since the people's health are tied together, policy makers and health care providers should use online social network to identify these relationships and its impacts on people's health and then find appropriate ways to promote society's health.

\section{References}

Abbasnezhad M, Rahmani A, Ghahramanian A, et al (2015). Cancer care burden among primary family caregivers of iranian hematologic cancer patients. Asian Pac J Cancer Prev, 16, 5499.

Attai DJ, Cowher MS, Al-Hamadani M, et al (2015). Twitter social media is an effective tool for breast cancer patient education and support: patient-reported outcomes by survy. J Med Int Res, 17, 188.

Azadmanjir Z, Safdari R, Ghazisaeidi M (2015). From self-care for healthy people to self-management for cancer patients with cancer portals. Asian Pac J Cancer Prev, 16, 1321.

Bakshy E, Rosenn I, Marlow C, et al (2012). The role of social networks in information diffusion. Proceedings of the 21st international conference on World Wide Web. ACM, 519-28.

Cain J (2011). Social media in health care: the case for organizational policy and employee education. Am J HealthSystem Pharmacy, 68, 1036-40.

Cannon G, Gupta P, Gomes F, et al (2012). Prevention of cancer and non-communicable diseases. Asian Pac J Cancer Prev, 13, 3-11.

Cavallo DN, Chou WYS, McQueen A, et al (2014). Cancer prevention and control interventions using social media: User-generated approaches. Cancer Epidemiol Biomarkers Prev, 23, 1953-6.

Centola D (2013). Social media as a tool in medicine. Circulat, 127, 2135-44.

Chelf JH, Agre P, Axelrod A, et al (2001). Cancer-related patient education: an overview of the last decade of evaluation and research. Oncology Nursing Forum. ONCOLOGY NURSING SOCIETY, 1139-48.

Courtney K (2013). The use of social media in healthcare: organizational, clinical, and patient perspectives. Stud Health Technol Inform, 183, 244.

Davoodi S, Safdari R, Ghazisaeidi M, et al (2015). Prevention and early detection of occupational cancers-a view of information technology solutions. Asian Pac J Cancer Prev, 16, 5607.

De la Torre-Diez I, Diaz-Pernas FJ, Anton-Rodriguez M (2012). A content analysis of chronic diseases social groups on Facebook and Twitter. Telemedicine e-Health, 18, 404-8.

DuBenske LL, Gustafson DH, Shaw BR, et al (2010). Webbased cancer communication and decision making systems: connecting patients, caregivers, and clinicians for improved health outcomes. Med Decis Making, 30, 732-44

Dunkel-Schetter C (1984). Social support and cancer: Findings based on patient interviews and their implications. J Social Issues, 40, 77-98.

Ell K (1984). Social networks, social support, and health status: A review. Social Service Review, 133-49.

Ellison NB (2007). Social network sites: Definition, history, and scholarship. J Computer-Med Communicat, 13, 210-30.

Ellison NB, Steinfield C, Lampe C (2007). The benefits of Facebook "friends:" Social capital and college students' use of online social network sites. J Computer Mediated Communicat, 12, 1143-68.

Fernsler JI, Manchester LJ (1996). Evaluation of a computerbased cancer support network. Cancer Practice, 5, 46-51.

Freeman HP (2004). Poverty, culture, and social injustice: determinants of cancer disparities. CA Cancer J Clin, 54, 72-7.

Garton L, Haythornthwaite C, Wellman B (1997). Studying online social networks. J Computer-Mediated Communicat, 3.

Glanz K, Rimer BK, Viswanath K (2008). Health behavior and health education: theory, research, and practice, John Wiley \& Sons.

Griffiths F, Cave J, Boardman F, et al (2012). Social networksThe future for health care delivery. Social Science Med, 75, 2233-41.

Hader AL, Brown ED (2010). Patient privacy and social media. AANA J, 78, 270-4.

Haghdoost A, Baneshi M, Haji-Maghsoodi S, et al (2014). Application of a Network Scale-up Method to Estimate the Size of Population of Breast, Ovarian/Cervical, Prostate and Bladder Cancers. Asian Pac J Cancer Prev, 16, 3273-7.

Harris K (1998). The informational needs of patients with cancer and their families. Cancer Practice, 6, 39-46.

Househ M, Borycki E, Kushniruk A (2014). Empowering patients through social media: the benefits and challenges. Health Informatics $J, \mathbf{2 0}, 50-8$.

Karver SB, Berger J (2010). Advanced care planningempowering patients for a peaceful death. Asian Pac $J$ Cancer Prev, 11, 23-5.

Kim BH, Wallington SF, Makambi KH, et al (2015). Social networks and physical activity behaviors among cancer survivors: data from the 2005 health information national trends survey. J Health Communicat, 1-7.

Kroenke CH, Kubzansky LD, Schernhammer ES, et al (2006). Social networks, social support, and survival after breast cancer diagnosis. J Clin Oncol, 24, 1105-11.

Kroenke CH, Kwan ML, Neugut AI, et al (2013). Social networks, social support mechanisms, and quality of life after breast cancer diagnosis. Breast Cancer Res Treat, 139, 515-27.

Kroenke CH, Michael Y, Tindle H, et al (2012). Social networks, social support and burden in relationships, and mortality after breast cancer diagnosis. Breast Cancer Res Treat, 133, 375-85.

Lee MH, Choi KS, Lee YY, et al (2013). Relationship between social network and stage of adoption of gastric cancer screening among the korean population. Asian Pac J Cancer Prev, 14, 6095-101.

Lutgendorf SK, De Geest K, Bender D, et al (2012). Social influences on clinical outcomes of patients with ovarian cancer. J Clin Oncol, 30, 2885-90.

Maher CA, Lewis LK, Ferrar K, et al (2014). Are health behavior change interventions that use online social networks effective? A systematic review. J Med Internet Res, 16.

Mislove A, Marcon M, Gummadi KP, et al (2007). Measurement and analysis of online social networks. Proceedings of the 
$7^{\text {th }}$ ACM SIGCOMM conference on internet measurement,. ACM, 29-42.

Mohammadzadeh N, Safdari R, Rahimi A (2013a). Multi-agent systems: effective approach for cancer care information management. Asian Pac J Cancer Prev, 14, 7757-9.

Mohammadzadeh N, Safdari R, Rahimi A (2013b). Positive and negative effects of IT on cancer registries. Asian Pac J Cancer Prev, 14, 4455-7.

Mohammadzadeh Z, Safdari R, Ghazisaeidi M, et al (2015). Advances in optimal detection of cancer by image processing; experience with lung and breast cancers. Asian Pac J Cancer Prev, 16, 5613.

Ogedegbe G, Cassells AN, Robinson CM, et al (2005). Perceptions of barriers and facilitators of cancer early detection among low-income minority women in community health centers. J National Med Associat, 97, 162.

Oliver JW, Kravitz RL, Kaplan SH, et al (2001). Individualized patient education and coaching to improve pain control among cancer outpatients. J Clin Oncol, 19, 2206-12.

Perkins JM, Subramanian S, Christakis NA (2015). Social networks and health: A systematic review of sociocentric network studies in low-and middle-income countries. Social Sci Med, 125, 60-78.

Pinquart M, Duberstein PR (2010). Associations of social networks with cancer mortality: a meta-analysis. Critical Reviews Oncol Hematol, 75, 122-37.

Rainey LC (1985). Effects of preparatory patient education for radiation oncology patients. Cancer, 56, 1056-61.

Rowley RD (2014). Professional social networking. Current Psychiatry Reports, 16, 1-6.

Sapp AL, Trentham-Dietz A, Newcomb PA, et al (2003). Social networks and quality of life among female long-term colorectal cancer survivors. Cancer, 98, 1749-58.

Scott J 2012. Social network analysis, Sage.

Shahrokni A, Mahmoudzadeh S, Lu BT (2013). In whom do cancer survivors trust online and offline? Asian Pacific $J$ Cancer Prev, 15, 6171-6.

Steinfield C, Ellison NB, Lampe C (2008). Social capital, selfesteem, and use of online social network sites: A longitudinal analysis. J Applied Developmental Psychol, 29, 434-45.

Suarez L, Lloyd L, Weiss N, et al (1994). Effect of social networks on cancer-screening behavior of older MexicanAmerican women. J National Cancer Institute, 86, 775-9.

Suarez L, Ramirez AG, Villarreal R, et al (2000). Social networks and cancer screening in four US Hispanic groups. Am J Prev Med, 19, 47-52.

Sugawara Y, Narimatsu H, Hozawa A, et al (2012). Cancer patients on Twitter: a novel patient community on social media. BMC Res Notes, 5, 699.

Ventola CL (2014). Social media and health care professionals: benefits, risks, and best practices. Pharmacy Therapeutics, 39, 491 .

Vogt TM, Mullooly JP, Ernst D, et al (1992). Social networks as predictors of ischemic heart disease, cancer, stroke and hypertension: incidence, survival and mortality. J Clin Epidemiol, 45, 659-66.

Von Muhlen M, Ohno-Machado L (2012). Reviewing social media use by clinicians. J Am Med Informatics Associat, 19, 777-81.

Yoon HJ, Tourassi G (2014). Analysis of online social networks to understand information sharing behaviors through social cognitive theory. biomedical science and engineering center conference (BSEC), 2014 annual oak ridge national laboratory, IEEE, 1-4. 